\title{
Sistem Pendukung Keputusan (SPK) Seleksi Penerimaan Siswa Baru (Studi Kasus di SMK TI Bali Global Denpasar)
}

\author{
Ni Made Rai Maryati, Made Windu Antara Kesiman, Ketut Agustini \\ Jurusan Pendidikan Teknik Informatika \\ Universitas Pendidikan Ganesha \\ email: divray25@gmail.com,dekndu@yahoo.com,eghee2006@gmail.com
}

\begin{abstract}
ABSTRAK
Tujuan yang ingin dicapai dalam penelitian ini yaitu merancang dan mengimplementasikan sebuah perangkat lunak Sistem Pendukung Keputusan (SPK) seleksi penerimaan siswa baru berbasis web yang mengambil studi kasus di SMK TI Bali Global Denpasar. Perangkat lunak ini diharapkan dapat membantu panitia penerimaan siswa baru sehingga proses seleksi siswa dapat dilakukan dengan lebih cepat, lebih mudah dan data yang dihasilkan sistem lebih akurat.

Perangkat lunak ini hanya menangani proses penyeleksian siswa melalui jalur Nilai Ujian Nasional (NUN). Proses penyeleksian ini terdiri dari dua proses utama yaitu proses penentuan bobot mata pelajaran ujian nasional dan proses perhitungan nilai total calon siswa. Bobot nilai ujian nasional untuk masing-masing program keahlian didapatkan dengan cara mengaitkan pekerjaan dengan keterampilan dan mata pelajaran ujian nasional. Nilai total calon siswa dihitung menggunakan metode Bayes. Nilai total ini dijadikan acuan untuk memutuskan apakan seorang calon siswa diterima atau tidak diterima. Dalam perancangan sistem digunakan DFD (Dataflow Diagram).

Bobot mata pelajaran ujian nasional pada program keahlian Rekayasa Perangkat Lunak adalah : Matematika $=0.5$, Bahasa Indonesia $=0.2$ dan Bahasa Inggris $=0.3$. Bobot mata pelajaran ujian nasional pada program keahlian Multimedia adalah : Matematika $=0.4$, Bahasa Indonesia $=0.2$ dan Bahasa Inggris $=0.4$. Bobot mata pelajaran ujian nasional pada program keahlian Teknik Komputer dan Jaringan adalah : Matematika $=0.5$, Bahasa Indonesia $=0.25$ dan Bahasa Inggris $=0.25$. Dalam implemetasi sistem, selain menangani proses perhitungan bobot dan nilai total, sistem juga menangani proses pembagian kelas, proses backup dan restore.
\end{abstract}

Kata kunci : Sistem Pendukung Keputusan, Seleksi Penerimaan Siswa Baru, SMK TI Bali Global Denpasar, Metode Bayes, DFD (Dataflow Diagram). 
Decision Support System (DSS)

Selection of New Students

(Case study in SMK TI Bali Global Denpasar)

by

Ni Made Rai Maryati, NIM 0915057117

Department of Computer Science Education

Email:divray25@gmail.com

\begin{abstract}
The objective of this research is to design and to implement the web-based software Decision Support System (DSS) selection of new students who took case studies in SMK TI Bali Global Denpasar. The software is expected to help the new student admissions committee so that the student selection process can be done more quickly, more easily and the resulting data is more accurate.

This software only deals with the process of selecting students through the National Examination Score. This selection process consists of two main processes namely weight determining process of the subjects of national examinations and the process of calculating the total value of prospective students. The weight of national exam scores for each programs expertise acquired by linking their tasks with their skills and national exam subjects. The total value of the prospective student is computed using Bayes's method. This total value is used as a reference for deciding whether a prospective student accepted or not accepted. In designing the system we use DFD (Data Flow Diagram).

The weights of the national exam subjects in Software Engineering program expertise are: Math $=0.5$, Indonesian Language $=0.2$, English $=0.3$. The Weights of the national exam subjects on the Multimedia program expertise are: Math $=0.4$, Indonesian Language $=0.2$, English $=0.4$. The Weights of the national exam subjects on the Computer Engineer and Networking program expertise are: Math $=0.4$, Indonesian Language $=0.2$, English $=0.4$. Beside weight determine process and total score calculation, this system also deal with class distribution process, backup and restore process.
\end{abstract}

Key words : Decision Support System, selection of new students, SMK TI Bali Global Denpasar, Bayes Method, DFD (Dataflow Diagram). 
ISSN 2089-8673

Jurnal Nasional Pendidikan Teknik Informatika (JANAPATI)

Volume 1, Nomor 2, Juli 2012

\section{Pendahuluan}

Perkembangan ilmu pengetahuan dan teknologi akhir-akhir ini begitu pesat. Perkembangan ini telah berdampak terhadap kehidupan manusia di berbagai bidang termasuk dalam bidang pendidikan. Dunia pendidikan di Indonesia sedang berbenah diri guna menghadapai tantangan di masa depan. Kebijakan pendidikan menengah saat ini diarahkan pada meningkatnya proporsi dan mutu SMK. Salah satu sekolah menengah kejuruan yang ada di Bali adalah SMK TI Bali Global Denpasar. Sekolah ini melakukan penyeleksian siswa melalui jalur Nilai Ujian Nasional (NUN) dan Tes Potensi Akademik. Namun dalam penelitian ini, penulis hanya membahas tentang penyeleksian siswa melalui jalur NUN.

Dalam penyeleksian siswa melalui jalur NUN, siswa tidak melaksanakan tes, namun siswa wajib mengumpulkan fotocopy ijasah SMP yang sudah dilegalisir. Dari ijasah tersebut akan didapatkan nilai Ujian Nasional siswa yang merupakan variabel yang menjadi tolak ukur dalam menentukan penerimaan dan penjurusan siswa, dimana proses ini menggunakan kaedah/metode Bayes. Dalam penerapan metode Bayes ini, yang dijadikan kriteria adalah mata pelajaran yang diujikan dalam ujian nasional (UN) dan bobot dari masing-masing kriteria ini dimasukkan langsung dalam bentuk angka. Proses perhitungan dilakukan secara manual dengan bantuan software Microsoft Excel. Kendala yang biasanya dialami yaitu kompleksitas perhitungan, kendala waktu dan dokumentasi data yang kurang baik sehingga seringkali menghambat proses pencarian data pada tahap selanjutnya.

Saat ini SMK TI Bali Global Denpasar sedang berupaya melakukan berbagai pembenahan, salah satunya adalah dengan merencanakan pengembangan sebuah perangkat lunak yang dapat membantu proses penyeleksian calon siswa baru. Dengan memanfaatkan perangkat lunak tersebut diharapkan proses penyeleksian calon siswa baru dapat dilakukan dengan lebih cepat, lebih mudah serta data yang dihasilkan lebih akurat, sehingga dapat meringankan tugas Panitia Penerimaan Siswa Baru dan penyeleksian bisa dilakukan secara murni tanpa ada manipulasi, disamping itu siswa tidak perlu menunggu hasil tes terlalu lama. Dengan demikian diharapkan sekolah bisa 
menyaring calon siswa baru yang memiliki kualitas yang baik serta meningkatkan citra sekolah di mata masyarakat.

Dalam Turban (2005) di kakatakan bahwa Sistem Pendukung Keputusan dapat diterapkan dalam bidang pendidikan, salah satu contohnya adalah CAPA (Cource Approval Procces Automatic) yaitu Sistem Pendukung Keputusan untuk proses persetujuan kuliah yang dikembangkan oleh Universitas Georgia. CAPA adalah sistem berbasis-web (intranet). Pengaplikasian CAPA dapat menghemat waktu dan biaya terutama bagi para penggunanya. Berdasarkan uraian di atas, tujuan yang ingin dicapai dalam penelitian ini adalah merancang dan mengimplementasikan SPK seleksi penerimaan siswa baru yang mengambil studi kasus di SMK TI Bali Global Denpasar.

Turban \& Aronson (2001) menyebutkan bahwa konsep sistem pendukung keputusan (SPK) muncul pertama kali pada awal tahun 1970-an oleh scott-Morton. Mereka mendefinisikan SPK sebagai suatu sistem interaktif berbasis komputer yang dapat membantu para pengambil keputusan dalam menggunakan data dan model untuk memecahkan persoalan yang bersifat tidak terstruktur.

Dalam Marimin (2004) dinyatakan bahwa Metode Bayes merupakan salah satu teknik yang dapat dipergunakan untuk melakukan analisis dalam pengambilan keputusan terbaik dari sejumlah alternatif dengan tujuan menghasilkan perolehan yang optimal. Untuk menghasilkan keputusan yang optimal, perlu dipertimbangkan beberapa kriteria. Pembuatan keputusan dengan metode Bayes dilakukan melalui upaya pengkwalifikasian kemungkinan terjadinya suatu kejadian dan dinyatakan dalam bilangan antara 0 dan 1 .

Persamaan Bayes yang digunakan untuk menghitung nilai setiap alternatif sering disederhanakan menjadi :

$$
\text { Total Nilai }=\sum_{j=1}^{m} \text { Nilai }_{i j}\left(\text { Krit }_{j}\right)
$$

dimana :

$$
\begin{array}{ll}
\text { Total Nilai }_{\mathrm{i}} & =\text { total nilai akhir dari alternatif ke-i } \\
\text { Nilai }_{\mathrm{ij}} & =\text { nilai alternatif ke-i pada kriteria ke-j }
\end{array}
$$




$$
\begin{array}{ll}
\text { Krit }_{\mathrm{j}} & =\text { tingkat kepentingan (bobot) kriteria ke-j } \\
\mathrm{i} & =1,2,3, \ldots \mathrm{n} ; \mathrm{n}=\mathrm{jumlah} \text { alternatif } \\
\mathrm{j} & =1,2,3, \ldots \mathrm{m} ; \mathrm{m}=\text { jumlah kriteria }
\end{array}
$$

\section{Analisis Dan Perancangan}

Masalah yang akan diteliti adalah proses seleksi siswa melalui jalur Nilai Ujian Nasional (NUN). Penelitian ini mengambil tempat di SMK TI Bali Global Denpasar yang berlokasi di jalan Tukad Citarum nomor 44, Panjer, Denpasar. Penelitian ini dilakukan mulai bulan Mei sampai dengan November 2010. Seleksi siswa melalui jalur NUN ini menggunakan metode Bayes untuk menghasilkan sebuah nilai total yang dijadikan acuan untuk memutuskan apakan seorang calon siswa diterima atau tidak diterima. Proses ini terdiri dari dua proses utama yaitu proses penentuan bobot mata pelajaran UN dan proses perhitungan nilai total calon siswa.

\section{Proses Pembobotan Mata Pelajaran UN}

Untuk mendapatkan bobot dari masing-masing mata pelajaran UN pada masingmasing program keahlian, langkahnya adalah sebagai berikut :

a. Rekam mata pelajaran UN, jenis pekerjaan dan keterampilan.

b. Tentukan keterampilan yang diperlukan oleh masing-masing jenis pekerjaan.

c. Tentukan mata pelajaran UN yang melatih masing-masing jenis keterampilan.

Setelah mendapatkan keterkaitan antara pekerjaan, keterampilan dan mata pelajaran UN, selanjutnya hitung bobot dari masing-masing mata pelajaran UN pada masing - masing program keahlian menggunakan persamaan di bawah ini.

$$
\mathrm{BM}=\frac{\mathrm{MP}}{\mathrm{MPJ}} \times 100 \%
$$

\section{Keterangan :}

$\mathrm{BM}=$ Bobot mata pelajaran

MP = jumlah satu jenis mata pelajaran (yang sama)

MPJ = jumlah seluruh mata pelajaran yang ada dalam suatu program keahlian 
Berikut ini adalah besarnya bobot mata pelajaran UN pada masing-masing program keahlian.

a) Rekayasa Perangkat Lunak (RPL)

Jenis pekerjaan untuk program keahlian RPL ada tiga yaitu operator software, pelaksana pemrograman software dan maintenance software (Direktorat Pendidikan Menengah Kejuruan, 2004a).

Tabel 1. Ruang lingkup pekerjaan bagi lulusan Program Keahlian RPL

\begin{tabular}{|c|l|l|}
\hline No & Jenis Pekerjaan & Kemampuan yang diperlukan \\
\hline 1 & $\begin{array}{l}\text { Operator software } \\
\text { aplikasi spesifik }\end{array}$ & Kemampuan untuk berkomunikasi dengan baik \\
\hline 2 & $\begin{array}{l}\text { Pelaksana pemrograman } \\
\text { software aplikasi } \\
\text { spesifik (pemrogram / } \\
\text { pengembang perangkat } \\
\text { lunak) }\end{array}$ & $\begin{array}{l}\text { Kemampuan intelektual, } \\
\text { Kemampuan untuk memecahkan masalah, } \\
\text { Kemampuan untuk menyederhanakan masalah, } \\
\text { Kemampuan menganalisa, } \\
\text { Punya rasa ingin tahu yang tinggi, } \\
\end{array}$ \\
\hline 3 & $\begin{array}{l}\text { Kaintainen software } \\
\text { aplikasi spesifik }\end{array}$ & $\begin{array}{l}\text { Kemampuan untuk menterjemahkan bahasa, } \\
\text { Kemampuan untuk berkomunikasi dengan baik, } \\
\text { Kemampuan untuk memecahkan masalah }\end{array}$ \\
\hline
\end{tabular}

Masing-masing kemampuan dihubungkan dengan mata pelajaran UN yang melatih keterampilan tersebut, seperti terlihat pada tabel 2.

Tabel 2. Keterkaitan anatara Ketrampilan dan Mata Pelajaran Ujian Nasional

\begin{tabular}{|c|l|l|}
\hline No & Ketrampilan / kemampuan yang dilatih & Mata Pelajaran \\
\hline 1 & kemampuan intelektual & $\begin{array}{l}\text { Matematika, Bahasa } \\
\text { Indonesia, Bahasa Inggris }\end{array}$ \\
\hline 2 & kemampuan untuk memecahkan masalah & Matematika \\
\hline 3 & kemampuan untuk menyederhanakan masalah & Matematika \\
\hline 4 & Kemampuan menganalisa & Matematika \\
\hline 5 & punya rasa ingin tahu yang tinggi & Matematika \\
\hline 6 & kemampuan untuk menterjemahkan bahasa & Bahasa inggris \\
\hline 7 & kemampuan untuk berkomunikasi dengan baik & $\begin{array}{l}\text { Bahasa indonesia, Bahasa } \\
\text { Inggris }\end{array}$ \\
\hline
\end{tabular}

Dari tabel 2, didapatkan perhitungan seperti di bawah ini : 
Bobot mata pelajaran $(\mathrm{BM})$ Matematika $=(5 / 10) \times 100 \%=50 \%=0.5$

Bobot mata pelajaran $(\mathrm{BM}) \mathrm{Bhs}$ Indonesia $=(2 / 10) \times 100 \%=20 \%=0.2$

Bobot mata pelajaran $(\mathrm{BM})$ Bhs Inggris $=(3 / 10) \times 100 \%=30 \%=0.3$

b) Multimedia (MM)

Jenis pekerjaan untuk program keahlian MM ada dua yaitu pembuat web dan pembuat animasi (Direktorat Pendidikan Menengah Kejuruan, 2004b).

Tabel 3. Ruang lingkup pekerjaan bagi lulusan Program Keahlian Multimedia

\begin{tabular}{|l|l|l|}
\hline No & Lingkup pekerjaan & Kemampuan yang diperlukan \\
\hline 1 & Pembuat web & Kreativitas \\
& & Kemampuan untuk berkomunikasi dengan baik \\
& & Kemampuan untuk menterjemahkan bahasa \\
& & Kemampuan memecahkan masalah \\
\hline 2 & Pembuat animasi & Kreativitas \\
& & Kemampuan untuk berkomunikasi dengan baik \\
\hline
\end{tabular}

Masing-masing kemampuan dihubungkan dengan mata pelajaran UN yang melatih keterampilan tersebut, seperti terlihat pada tabel 4.

Tabel 4. Keterkaitan antara Ketrampilan dan Mata Pelajaran UN

\begin{tabular}{|c|l|l|}
\hline No & Ketrampilan / kemampuan yang dilatih & Mata Pelajaran \\
\hline 1 & Kreativitas & Matematika \\
\hline 2 & kemampuan untuk memecahkan masalah & Matematika \\
\hline 3 & kemampuan untuk menterjemahkan bahasa & Bahasa inggris \\
\hline 4 & kemampuan untuk berkomunikasi dengan baik & Bahasa indonesia, Bahasa Inggris \\
\hline
\end{tabular}

Dari tabel 4, didapatkan perhitungan seperti di bawah ini :

Bobot mata pelajaran $(\mathrm{BM})$ Matematika $=(2 / 5) \times 100 \%=40 \%=0.4$

Bobot mata pelajaran $(\mathrm{BM}) \mathrm{Bhs}$ Indonesia $=(1 / 5) \times 100 \%=20 \%=0.2$

Bobot mata pelajaran $(\mathrm{BM})$ Bhs Inggris $=(2 / 5) \times 100 \%=40 \%=0.4$

c) Teknik Komputer dan Jaringan (TKJ)

Jenis pekerjaan untuk program keahlian TKJ ada dua yaitu teknisi komputer dan administrator jaringan (Direktorat Pendidikan Menengah Kejuruan, 2004c). 
Tabel 5. Ruang lingkup pekerjaan bagi lulusan Program Keahlian TKJ

\begin{tabular}{|l|l|l|}
\hline No & Jenis Pekerjaan & Kemampuan yang diperlukan \\
\hline 1 & Teknisi Komputer & $\begin{array}{l}\text { Kemampuan untuk memecahkan masalah } \\
\text { Punya rasa ingin tahu yang tinggi } \\
\text { Kemampuan untuk berkomunikasi dengan baik }\end{array}$ \\
\hline 2 & Administrator Jaringan & Kemampuan untuk memecahkan masalah \\
\hline
\end{tabular}

Masing-masing kemampuan dihubungkan dengan mata pelajaran UN yang melatih keterampilan tersebut, seperti terlihat pada tabel 6 .

Tabel 6. Keterkaitan anatara Ketrampilan dan Mata Pelajaran UN

\begin{tabular}{|l|l|l|}
\hline No & Ketrampilan / kemampuan yang dilatih & Mata Pelajaran \\
\hline 1 & kemampuan untuk memecahkan masalah & Matematika \\
\hline 2 & punya rasa ingin tahu yang tinggi & Matematika \\
\hline 3 & kemampuan untuk berkomunikasi dengan baik & Bahasa indonesia, Bahasa Inggris \\
\hline
\end{tabular}

Dari data pada tabel 6 maka didapatkan perhitungan seperti di bawah ini :

Bobot mata pelajaran $(\mathrm{BM})$ Matematika $=(2 / 4) \times 100 \%=50 \%=0.5$

Bobot mata pelajaran $(\mathrm{BM}) \mathrm{Bhs}$ Indonesia $=(1 / 4) \times 100 \%=25 \%=0.25$

Bobot mata pelajaran $(\mathrm{BM})$ Bhs Inggris $=(1 / 4) \times 100 \%=25 \%=0.25$

2. Proses Perhitungan Nilai Total dan Peringkat Calon Siswa

Perhitungan nilai total calon siswa menggunakan metode Bayes, dimana nilai UN calon siswa sebagai kriteria dan calon siswa sebagai alternatif pilihan.

dimana :

$$
\mathrm{NT}_{\mathrm{i}}=\sum_{\mathrm{j}=1}^{\mathrm{m}} \mathrm{N}_{\mathrm{ij}}\left(\mathrm{B}_{\mathrm{j}}\right)
$$

$$
\begin{array}{ll}
\mathrm{NT}_{\mathrm{i}} & =\text { nilai total dari calon siswa yang ke- } \mathrm{i} \\
\mathrm{N}_{\mathrm{ij}} & =\text { nilai dari calon siswa yang ke-i pada mata pelajaran ke- } \mathrm{j} \\
\mathrm{B}_{\mathrm{j}} & =\text { bobot mata pelajaran ke- } \mathrm{j} \\
\mathrm{i} & =1,2,3, \ldots \mathrm{n} ; \mathrm{n}=\text { jumlah siswa } \\
\mathrm{j} & =1,2,3, \ldots \mathrm{m} ; \mathrm{m}=\text { mata pelajaran }
\end{array}
$$

Jika dibuat tabel keputusan seleksi siswa, misalnya untuk program keahlian RPL, akan terlihat seperti yang ditunjukkan pada tabel 7. 
Tabel 7. Contoh tabel keputusan seleksi siswa

\begin{tabular}{|l|c|c|c|c|c|}
\hline \multirow{2}{*}{$\begin{array}{c}\text { Calon siswa } \\
\text { (alternatif pilihan) }\end{array}$} & \multicolumn{3}{|c|}{ Mata pelajaran (kriteria) } & Nilai calon & Pering \\
siswa & kat \\
\cline { 2 - 4 } 1. Putra & Bahasa Indonesia & Bahasa Inggris & Matematika & 7,2 & 2 \\
\hline 2. Merlin & 7 & 6 & 8 & 6,1 & 5 \\
\hline 3. Angelica & 6 & 8 & 5 & 7,5 & 1 \\
\hline 4. Ariadi & 7 & 7 & 8 & 6,6 & 3 \\
\hline 5. Wangi & 8 & 5 & 7 & 6,5 & 4 \\
\hline Bobot mata pelajaran & 0,2 & 8 & 5 & & \\
\hline
\end{tabular}

Berikut ini adalah Diagram Konteks SPK Seleksi Penerimaan Siswa Baru.

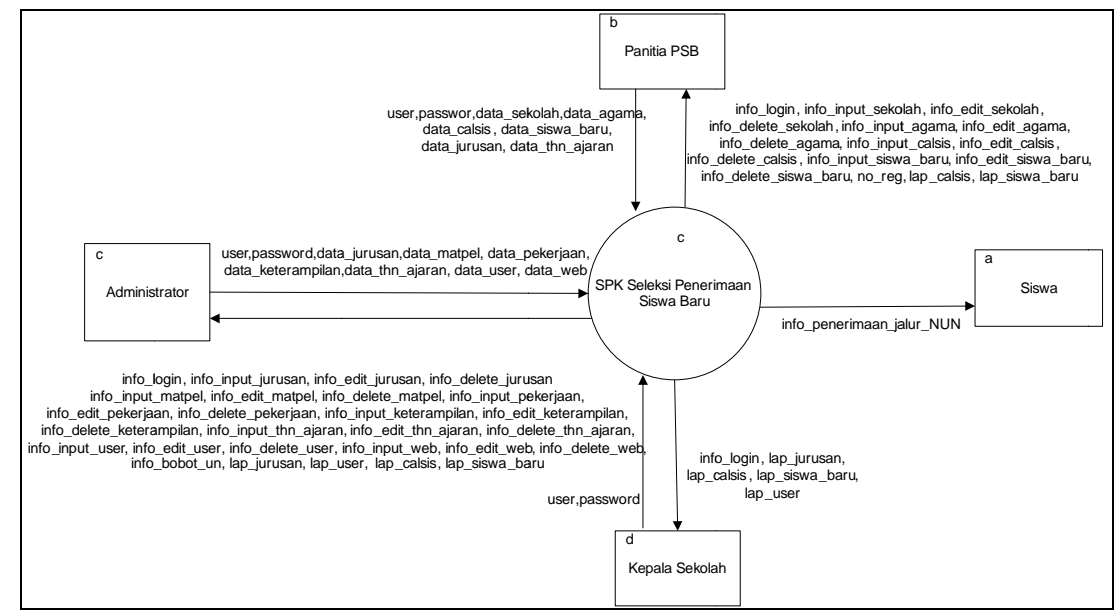

Gambar 1. Diagram Konteks SPK Seleksi Penerimaan Siswa Baru

Pada Diagram Konteks SPK Seleksi Penerimaan Siswa Baru terdapat empat entitas yaitu Siswa, Panitia PSB(Penerimaan Siswa Baru), Administrator dan Kepala Sekolah. Siswa dapat menerima info penerimaan siswa baru melalui jalur NUN yang dihasilkan oleh sistem. Panitia PSB memiliki hak akses terhadap pengelolaan data siswa serta data terkait lainnya. Administrator memiliki hak akses terhadap pengelolaan data user, proses seleksi siswa, pemagian kelas, proses backup dan restore, pengelolaan web sekolah serta data terkait lainnya sedangkan kepala sekolah dapat melihat laporan yang dihasilkan oleh sistem.

Relasi Basis Data SPK Seleksi Penerimaan Siswa Baru dapat digambarkan sebagai berikut. 
ISSN 2089-8673

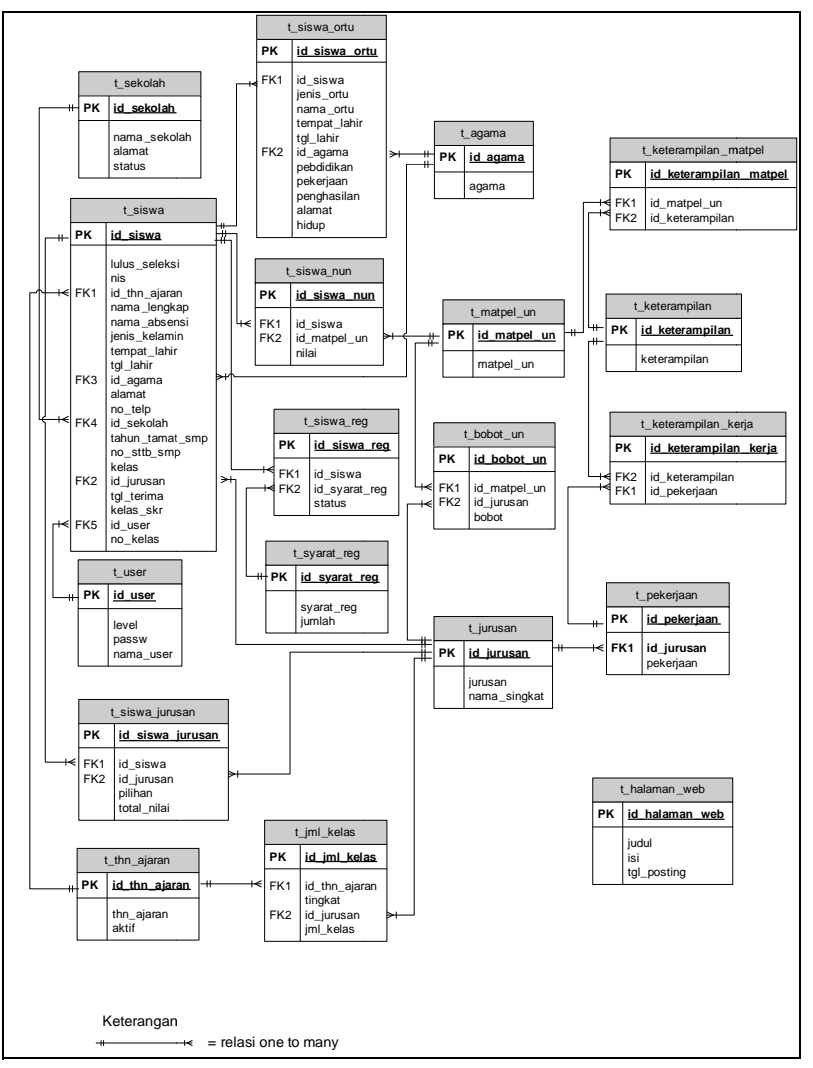

Gambar 2 Relasi Basis Data SPK Seleksi Penerimaan Siswa Baru

\section{Implementasi Dan Pengujian}

Dalam implementasi sistem spesifikasi perangkat keras yang digunakan diantaranya : Komputer Pentium IV Dual Core 2.2 GHz, RAM 1 GB dan Hardisk 80 GB. Sementara untuk spesifikasi perangkat lunak yang digunakan diantaranya : Sistem operasi Windows XP Profesional SP 2, Web server Apache 2.2.6, Bahasa pemrograman berbasis web PHP 5.2.3, Database MySQL 5.0.45 dan Web browser Internet Explorer 7.

Lokasi penempatan sistem ada dua yaitu di jaringan lokal dan online di Internet. Hal ini dilakukan agar proses pengelolaan data bisa lebih cepat dan sistem yang berjalan di jaringan lokal relatif lebih aman karena pengguna yang bisa mengakses sistem jumlahnya terbatas. Sistem yang berjalan di jaringan lokal digunakan untuk melakukan pengelolaan data serta penyeleksian siswa, sedangkan sistem yang online berfungsi sebagai website sekolah yang akan menginformasi hasil penyeleksian siswa serta berita terkait lainnya. Agar data yang dikelola pada web lokal bisa dipindahkan ke web 
online, maka pada web lokal disediakan fasilitas backup data dan pada web online disediakan fasilitas restore data.

Berikut ini adalah tampilan beberapa layar antarmuka sistem.

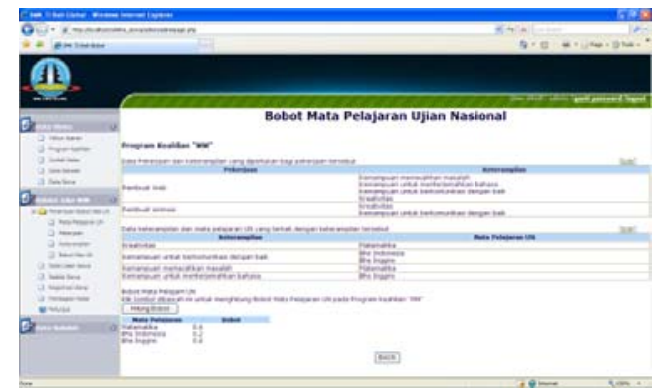

Gambar 3 Form pembobotan nilai UN

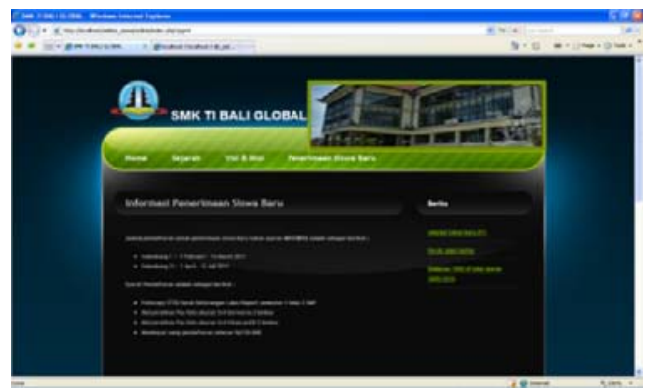

Gambar 4 Form informasi pengadaan calon siswa

Dari hasil pengujian dapat disimpulkan bahwa sistem bisa menangani masukan yang tidak valid dan menampilkan output sesuai dengan apa yang direncanakan serta melaksanakan mekanisme perhitungan dan logika dengan benar.

\section{Penutup}

Simpulan yang dapat diambil adalah sebagai berikut :

1. Untuk menggambarkan rancangan sistem, digunakan DFD (Data Flow Diagram).

Rancangan basis data dibuat dalam bentuk diagram relasi basis data. Rancangan form dibuat dalam bentuk gambar yang menyerupai tampilan dari form yang akan dibuat.

2. Implemetasi SPK seleksi siswa menghasilkan suatu program aplikasi yang menangani proses-proses antara lain : manipulasi dan pencarian data, pelaporan / cetak data, pembobotan nilai UN, seleksi siswa, pembagian kelas, backup dan restore data

Adapun saran yang dapat diberikan dalam upaya penyempurnaan sistem yaitu diharapkan agar sistem bisa mengolah data dalam bentuk file gambar serta mampu menangani proses penyeleksian siswa melalui jalur lain. 


\section{DAFTAR PUSTAKA}

Direktorat Pendidikan Menengah Kejuruan. 2004a. Kurikulum SMK 2004 Bidang Keahlian Teknologi Informasi dan Komunikasi Program Keahlian Rekayasa Perangkat Lunak. Jakarta: Direktorat Pendidikan Menengah Kejuruan.

------. 2004b. Kurikulum SMK 2004 Bidang Keahlian Teknologi Informasi dan Komunikasi Program Keahlian Multimedia. Jakarta: Direktorat Pendidikan Menengah Kejuruan.

------. 2004c. Kurikulum SMK 2004 Bidang Keahlian Teknologi Informasi dan Komunikasi Program Keahlian Teknik Komputer dan Jaringan. Jakarta: Direktorat Pendidikan Menengah Kejuruan.

Marimin. 2004. Pengambilan Keputusan Kriteria Majemuk. Yogyakarta: Andi.

Turban, Efraim et.al. 2005. Sistem Pendukung Keputusan dan Sistem Cerdas terjemahan dwi prabantini. Decision Support System and Intelligent System. 2005. Edisi ke-7. Yogyakarta: Andi 